\title{
TRADUCIR Y SER TRADUCIDO: EL TALLER DE TRADUCCIÓN LITERARIA DE LA LAGUNA Y KIEL, Y SOBRE UNA CONFIDENCIA DEL MAR GRIEGO EN ALEMÁN
} Javier GÓMEZ-MONTERO - Christina Johanna BISCHOFF

Christian-Albrechts-Universität zu Kiel

Universität Paderborn

\section{EL TALLER DE TRADUCCIÓN LITERARIA DE LA LAGUNA}

\section{Javier GÓMEZ-MONTERO}

Christian-Albrechts-Universität zu Kiel

Más allá, o más acá, de la filología, de la historia literaria y de la crítica, la traducción parece inscribirse en pleno centro de la experiencia estética, es decir, en el corazón mismo de la literatura, cuyos problemas «ilustra»y representa de manera paradigmática (Sánchez Robayna, 1996: 18).

$\mathrm{L}$ a traducción es para Andrés Sánchez Robayna un campo esencial tanto en la creación literaria como en su actividad académica. Escribir y traducir poesía constituye un único discurso en su escritura, pues fuente y objeto de ambas es el ansia de representación pese a su dificultad o pese a la insuficiencia del lenguaje y a expensas de la (re)creación de realidad y como expresión estética del pensamiento a partir de una descarnada reflexión sobre la posición del ser humano en el mundo.

Esa dimensión antropológica es central en el concepto de poesía y de traducción literaria propugnado por Andrés Sánchez Robayna quien, desde sus estudios universitarios en Barcelona (con sus célebres traducciones de Joan Brossa y con sus primeros poemas), acertó a cultivar ambas modalidades de escritura poética y que, ya en Tenerife y desde la Universidad de La Laguna, se convirtió en el spiritus rector del Taller de Traducción Literaria allí enraizado desde los años noventa.

Esa conjunción de poesía y traducción pone de manifiesto el papel central que Andrés Sánchez Robayna les confiere en su visión de las relaciones entre cultura y sociedad, instituciones académicas 
y formación del hombre contemporáneo como ser simbólico y capaz de creación mediante el lenguaje y la escritura, capaz así mismo de recreación del mundo gracias a la lectura y la traducción que, precisamente y según expresaba en el prólogo al volumen Literatura y traducción: caminos actuales (Sánchez Robayna, 1996: 9-18), entiende como «intercambio cultural en el sentido amplio, esto es, antropológico, de la idea de cultura. No solo se traducen los idiomas; con ellos, y con las tradiciones culturales, se traducen también las actitudes, los símbolos, las conductas» (Sánchez Robayna, 1996: 10).

Desde 1995, Andrés Sánchez Robayna ha desarrollado con el Taller de Traducción Literaria en la Universidad de La Laguna, una actividad pionera en el campo de la traducción literaria en España, siguiendo la huella de los encuentros de la abadía de Royaumont al norte de París y el Centre de Poésie et Traduction que allí dirigió durante muchos y buenos años Rémy Hourcade con diversas publicaciones, entre las que cuenta la colección Les Cahiers de Royaumont. Con una impronta muy personal de Andrés Sánchez Robayna ganó pronto cuerpo una colección por él dirigida y que hoy cuenta con traducciones colectivas o individuales de textos de John Keats, Gustave Flaubert, Claude Esteban, Jacques Ancet, Paolo Valesio, William Wordsworth, Geoffrey Hill, y otros muchos autores.

El modelo de traducción colectiva aplicado por el Taller en La Laguna lo concisa el poeta canario mismo en la solapa de los libros del Taller con los siguientes términos:

El Taller de Traducción Literaria de la Universidad de La Laguna, creado en junio de 1995, e integrado por profesores y alumnos de la Facultad de Filología, persigue dos objetivos fundamentales: estudiar y difundir las cuestiones y los problemas de los que se ocupan la traducción literaria y la Traductología, de una parte, y, de otra, emprender diferentes trabajos prácticos de traducción -tanto la tradicional o individual como la colectiva-, sobre todo de aquellos textos que por su nivel de elaboración o de "información estética" presenten un grado especial de dificultad y de complejidad. Los miembros del Taller realizan también la traducción tradicional o individual; esas traducciones son luego examinadas y discutidas colectivamente.

Se trata pues de versiones largamente elaboradas, muy corregidas en grupo, resultado de multitud de sugerencias y propuestas, donde los participantes se han debido ejercitar en deponer su ego y orgullo por su propio trabajo practicando la humildad. Traducir así es intensidad y sufrimiento, es un proceso intelectual atento a soluciones pragmáticas en volandas de la creación y sujeto a una dinámica de grupo cuyo objetivo es el mejor resultado final.

Quizá los libros antológicos publicados por Pre-Textos (De Keats a Bonnefoy en 2010, Ars poetica. Versiones de poesía moderna en 2011, y Las llamas sobre el agua en 2016) sean ejemplo granado de la trascendencia de los resultados literarios de la labor. Es además muestra de la consolidación de la reflexión traductológica desarrollada desde La Laguna el Boletín del Taller de Traducción Literaria, con numerosas entregas que dan cuenta de perspectivas y trabajos también procedentes de otros lugares.

Cabe resumir las técnicas y métodos de trabajo del Taller de La Laguna, concordantes con las del Taller de Traducción Literaria que en Kiel yo mismo dirijo desde hace quince años, en las siguientes fórmulas: 
- Traducción colectiva (a partir, en general, de la propuesta de uno de los miembros del Taller, y generada a partir de las transformaciones del texto verso a verso, línea por línea),

- Traducción individual (que es una base muy dinámica, pues sirve de matriz de alternativas), y revisada (variante de gran efectividad, aunque a veces ocasión de susceptibilidades),

- Traducción comparada (que suele ser muy útil para la docencia),

- Traducción de autor (pero contrastada a posteriori, con las ideas de los miembros del Taller en alguna de cuyas reuniones suele participar también ese traductor profesional).

A partir de esa pauta que nos vino de la Laguna, e incorporando el principio de una traducción lectorada con una lectura editorial profesionalizada (lo que se reveló pronto como algo absolutamente y siempre necesario), también en Kiel iniciamos una colección con traducciones al alemán que hoy cuenta con doce títulos. Si Andrés Sánchez Robayna nos dio la pauta con su visionaria iniciativa tinerfeña para traducir al español textos europeos centrales de la tradición literaria moderna y de la escritura contemporánea, desde Kiel nos estamos esforzando en dar entrada en Europa a textos poéticos y narrativos de la literatura española (y también gallega, de acuerdo con mi origen), entre los que ya cuentan Antonio Gamoneda, Gonzalo Torrente Ballester, Ángel González, María Zambrano y Andrés Sánchez Robayna, basados muchas veces en seminarios con participación de los autores, o de sus estudiosos, sea en Kiel o fuera, en el marco de los Encuentros de Traductores y Escritores que desde 2006 coordino en Castrillo de los Polvazares (León): www.uni-kiel.de/lites/traductores.html

Uno de los exponentes más conspicuos de nuestro taller es la traducción al alemán, realizada por Christina Johanna Bischoff y lectorada por Karina Gómez-Montero de Sobre una confidencia del mar griego de Andrés Sánchez Robayna, que la traductora misma presenta en este artículo, y a cuyas reflexiones nos atenemos a continuación.

\section{Bibliografía}

SÁNChez RobAynA, A. (1996): «Prólogo», en VALESIO, P. / DíAZ, R.-J., Literatura y traducción: caminos actuales. Tenerife, Universidad Internacional Menéndez Pelayo, pp. 9-18.

\section{Publicaciones del Taller de Traducción Literaria de La Laguna (1996-2016)}

Aglio, F., dall' (2008): Hic et Nunc. Trad. S. Pelusi. Madrid, Huerga y Fierro.

- (2012): La otra luna. Trad S. PELUSI. Montblanc, Igitur.

ANCET, J. (1996): La habitación vacía. La Laguna, Taller de Traducción Literaria de la Universidad de La Laguna, Ediciones Canarias.

- (2013): Puesto que él es este silencio. Prosa para Henri Meschonnic. Trad. J. CABello y R. HERNÁNDEZ. Madrid, Salto de Página.

Crane, H. (2013): El puente. Trad. S. Burgess y M. FernándeZ De SEvilla. Valencia, Pre-Textos. 
Esteban, C. (1996): Siete días de ayer. La Laguna, Taller de Traducción Literaria de la Universidad de La Laguna, Ediciones Canarias.

FAbIEN, J. (2011): París en sueños. Trad. B. NAvarro. Madrid, Círculo de Bellas Artes.

Flaubert, G. (1997): Diccionario de lugares comunes. Trad. Á. Mollá y F. SAINZ. La Laguna, Taller de Traducción Literaria de la Universidad de La Laguna, Ediciones Canarias.

HILL, G. (2003): Veintisiete poemas. Versión e introducción de J. DocE. Tegueste, Taller de Traducción Literaria de la Universidad de La Laguna.

JABÈs, E. (2002): Un extranjero con, bajo el brazo, un libro de pequeño formato. Trad. C. GonZÁlez de Uriarte y M. Privat. Barcelona, Galaxia Gutenberg.

Johnson, S. (2003): Prefacio a Shakespeare. Trad. C. ToledAno. Barcelona, Taller de Traducción Literaria de la Universidad de La Laguna, Acantilado.

KeAts, J. (1997): Oda a una urna griega. La Laguna, Taller de Traducción Literaria de la Universidad de La Laguna, Ediciones Canarias.

LuzI, M. (2009): Antología poética. Trad. J. DíAz ARMAS. Barcelona, Galaxia Gutenberg / Círculo de Lectores.

Marçal, M. M. (2004): Deshielo. Trad. C. Curell. Montblanc, Igitur.

NoËL, B. (1998): El síndrome de Gramsci. Trad. G. RocHEL. La Laguna, Taller de Traducción de la Universidad de La Laguna, Ediciones Canarias.

Pont, J. (2008): Vuelo de cenizas. Trad. C. Curell. Valencia, Pre-Textos.

SAINT-SIMON, C.-H. de (2011): Sobre la reorganización de la sociedad europea. Trad. B. NAVARRO. Madrid, Círculo de Bellas Artes.

SÁnchez Robayna, A. (ed.) (2010): De Keats a Bonnefoy. Valencia, Pre-Textos. , ed. (2011): Ars poetica. Versiones de poesía moderna. Valencia, Pre-Textos.

- ed. (2016): Las llamas sobre el agua. Valencia, Pre-Textos.

—, ed. (2011-): Boletín del Taller de Traducción Literaria. 26 números. La Laguna, Taller de Traducción de la Universidad de La Laguna.

SEFERIS, G. (2009): Tres poemas secretos. Trad. I. GARCÍA GÁlVEZ. Madrid, Abada Editores.

Stevens, W. (2003): De la simple existencia. Trad. A. SÁnChEZ RoBAynA. Barcelona, Galaxia Gutenberg.

VAléry, P. (2007): Cuadernos. Trad. M. Privat, A. SÁnchez Robayna y F. Sainz. Barcelona, Galaxia Gutenberg.

VAlesio, P. (1996): Sonetos profanos y sacros. La Laguna, Taller de Traducción Literaria de la Universidad de La Laguna, Ediciones Canarias.

WORDWORTH, W. (1999): El preludio. La Laguna, Taller de Traducción Literaria de la Universidad de La Laguna, Ediciones Canarias. 


\section{Publicaciones del Taller de Traducción Literaria de Kiel (2006-2018)}

Aparicio, J. P. - Mateo Díez, L. - Merino, J. M. (2012): Worte im Schnee, Ein Filandón. Kiel, Taller de Traducción Literaria, Ludwig. Bd. VIII.

Fernán Vello, M. A. - Rivas, M. - Valcárcel, X. L. - Álvarez CácCamo, X. M. (2010): Ein Rosenfeuer, das uns verstört, 4 Dichter aus Galicien/4 poetas galegos. Kiel, Taller de Traducción Literaria, Ludwig. Bd. VI.

Ferretti, V. A. - Gómez-Montero, J. (eds.) (2006): Dieser klingende Schatten, die Musik. Eine zweisprachige. Anthologie (Poemas/Gedichte). Kiel, Taller de Traducción Literaria, Ludwig. Bd. I.

GAmonedA, A. (2007): Esta luz/Dieses Licht. Eine Anthologie 1947-2005. Kiel, Taller de Traducción Literaria, Ludwig. Bd. II.

García LorCA, F. (2018): Bernarda Albas Haus - Bluthochzeit. Trad. K. GóMEZ-MonTERo. Kiel, Taller de Traducción Literaria, Ludwig. Bd. XII.

Gómez-MonTERo, J. (ed.) (2012): Im Jakobsland, Eine literarische Kartographie des Jakobsweges, im Nordwesten Spaniens, Erzählungen - Gedichte - Notizen. Kiel, Taller de Traducción Literaria, Ludwig. Bd. IX.

- (2017): Wege und Umwege nach Compostela. Ein literarischer Jakobsweg in Castilla y León. Erzählungen, Gedichte, Essays und Erinnerungen von 25 spanischen Autoren. Kiel, Taller de Traducción Literaria, Ludwig. Bd. VII.

Gómez-Montero, K. - Sinjen, B. (eds.) (2013): Allá en el Norte/Dort im Norden, Gedichte und Erzählungen. Kiel, Taller de Traducción Literaria, Ludwig. Bd. X.

GonZÁleZ, Á. (2009): Manchmal, im Oktober. Kiel, Taller de Traducción Literaria, Ludwig. Bd. IV. SÁNCHEZ RoBAYNA, A. - TÀPIES, A. (2009): Was das griechische Meer mir anvertraute/Sobre una confidencia del mar griego. Trad. C. J. BISCHOFF. Kiel, Taller de Traducción Literaria, Ludwig. Bd. V.

Torrente Ballester, G. (2007): Santiago de Compostela/Ein Pilgerlesebuch. Kiel, Taller de Traducción Literaria, Ludwig. Bd. III.

ZAmbrano, M. (2015): Europa und die Stadt. Gesammelte Aufsätze. Ed. J. GóMEZ-MonTERo - A. I. ERDOZÁIN. Kiel, Taller de Traducción Literaria, Ludwig. Bd. XI. 


\title{
2. LA TRADUCCIÓN AL ALEMÁN DE SOBRE UNA CONFIDENCIA DEL MAR GRIEGO DE ANDRÉS SÁNCHEZ ROBAYNA
}

\author{
Christina Johanna BISCHOFF \\ Universität Paderborn \\ christina.bischoff@uni-paderborn.de
}

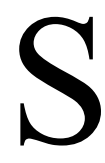

on más que conocidos los problemas que conlleva la traducción de poesía, que dificulta la tarea del traductor por su lenguaje en general condensado y, por lo tanto, complejo y plurivalente. Son conocidas y ampliamente discutidas también las posturas que hay al respeto, desde el rechazo de cualquier traducción hasta su acogida eufórica, basada en la confianza de que el traductor, a la hora de traducir, crea su propia obra nueva, con conceptos intermedios que subrayan la «negociación» (Eco, 2003: 6 y passim) que supone cualquier traducción. Las reflexiones que siguen no pretenden ser una contribución a estas cuestiones. Su meta es más modesta: pretenden describir algunos problemas concretos que planteaba la traducción al alemán de Sobre una confidencia del mar griego de Andrés Sánchez Robayna (poemario publicado en 2005 con dibujos de Antoni Tàpies) y presentar las soluciones, desde luego parciales, por las que opté al respecto.

Dos observaciones que conciernen tanto la edición como el proceso de traducción se imponen. Primero, la edición alemana de Sobre una confidencia del mar griego es una edición bilingüe. Teniendo en cuenta que el español es un idioma cada vez más conocido en Alemania, la traducción aspiraba más a facilitar el acceso a esta poesía que a sustituir el original. Este objetivo no implicaba, como se suele sospechar en tal caso, una sobrevaloración del contenido frente a la forma. Sí que implicaba una aproximación al original que planteaba respetar, en la medida de lo posible, los aspectos formales y semánticos que priorizaba el original, por muy seductor que fuera seguir la pauta del propio poeta y condensar una experiencia —en mi caso, la experiencia de leer la confidenciadándole una forma nueva.

En segundo lugar, cabe mencionar que la traducción de Sobre una confidencia del mar griego al alemán fue una obra primeriza. Hay que destacar que no podría haber visto la luz sin el respaldo de Javier Gómez-Montero, director del Taller de Traducción Literaria en la Universidad de Kiel, y de Karina Gómez-Montero, la lectora literaria, cuyo apoyo a la hora de discutir problemas concretos relacionados con la traducción fue inestimable. Este comentario, además de ser agradecimiento, 
quiere advertir que las líneas que siguen reflejan 'negociaciones', para retomar el término de Eco, en un sentido muy concreto. Negociaciones dentro del grupo de traductores del Taller a la hora de presentar unos primeros esbozos, negociaciones con Karina, negociaciones, en fin, con el propio Andrés Sánchez Robayna.

Sobre una confidencia del mar griego, precedido de Correspondencias contiene, como indica el título, dos partes: una serie de poemas reunidos bajo el título de Correspondencias, y otra serie —en realidad, se trata, según me comunicó Andrés Sánchez Robayna, de un solo poema en diversos fragmentos- titulada Sobre una confidencia del mar griego. Las dos partes comparten un mismo tema, que es la transitoriedad del ser; lo enfocan, sin embargo, de manera muy distinta. En Correspondencias, apenas encontramos un poema que no hable de la fugacidad del tiempo y de la muerte. Hay poemas que se refieren de manera explícita a la muerte humana («Tu cuerpo ya...»; «Homenaje»; «Gerberas amarillas...»; «Cementerio del Testaccio»; «Madrid, para una elegía») y otros que hablan de la fragilidad de lo creado por los hombres («Verás, incomprensible...»; «Madera de una silla rota...»; «Una sombra»; «El niñodiós anduvo...»). En general, los poemas se presentan como transcripción de un proceso de subjetivación de los fenómenos circundantes, y es este mismo proceso el que les impone su propia temporalidad. Como contrabalanza, la perpetuidad de la luz («Tras las columnas...», «La calle blanca») y de la piedra («Sobre un trono de piedra») parece prometer una salvación posible dentro de un mundo en el que «la muerte lo pide todo» («omnia mors poscit», en «Gerberas amarillas» (Sánchez Robayna, 2005: 21)). Una dimensión metapoética reflexiona, en Correspondencias, sobre esta conditio humana, inscribiendo los poemas en una tradición lírica que no sólo considera que la poesía es la expresión de una negatividad irremediable, sino que concibe esta negatividad como el fondo mismo de la voz poética:

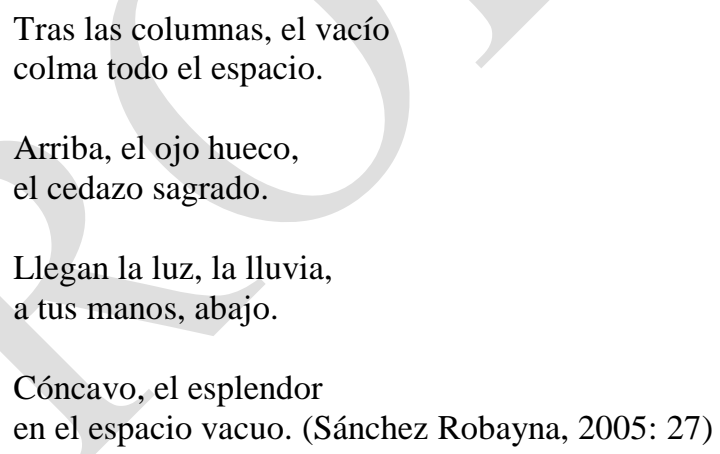

La primera estrofa propone, con «columnas» y «espacio», una configuración cuyo referente puede ser tanto la realidad extratextual como la letra y la página blanca del poema. La antítesis «el vacío / colma» alude a una plenitud en la ausencia; la última estrofa retomará esta figura cuando habla de un «espacio vacuo» colmado, esta vez, por la luz. La negatividad a la que alude el poema se conceptualiza, por lo tanto, como iluminación: o bien iluminación de una trascendencia anhelada, o bien iluminación profana (Walter Benjamin), es decir una experiencia de sentido a partir de una experiencia de lectura. El ojo, que podría ser el sol o el ojo del mismo lector, permite y alimenta 
ambas lecturas, lo que nos permite entender las manos que reciben agua y lluvia como alusión al proceso mismo de escribir.

En Sobre una confidencia del mar griego encontramos, si es lícito decirlo así, otro lenguaje distinto al de Correspondencias. Las referencias a la muerte siguen presentes, pero se enfocan de otra manera. El sujeto lírico se sumerge en una experiencia del presente. El acto de percibir está en el primer plano y actúa como artífice de una auto-constitución subjetiva; el poema, que cuenta este proceso de auto-constitución, dispone por lo tanto de un sustrato narrativo ${ }^{1}$. El avance de la narración sin embargo no es lineal; las metamorfosis del sujeto son multiformes: el tú lírico que «avizora[]» la «pupila solar» (Sánchez Robayna, 2005: 37) y que no deja de ver ni de observar (Sánchez Robayna, 2005: 43; 51; 55; 65; 73), pero también las luces del mar (Sánchez Robayna, 2005: 37; 39; 41; 43; $47 ; 51 ; 53 ; 57 ; 59 ; 61 ; 63 ; 67 ; 71)$ son algunos elementos de un campo semántico del 'ver', que se completa por - y a veces se confunde con- un correspondente campo semántico del 'oír' (Sánchez Robayna, 2005: 39; 45; 69; 71; 73). La estructura dialógica, presente en ocasiones en Correspondencias, adquiere protagonismo en Sobre una confidencia del mar griego, donde dominan las referencias a un tú lírico; esta estructura va acompañada de un lenguaje sintácticamente sencillo y, como también es el caso en Correspondencias, a menudo elíptico. Las imágenes, sin embargo, no siempre comparten esta sencillez: «Escuchaste / [...] / un rumor [...]. // Caía, desde el tímpano, / en el espacio / de lo no dicho [...]» (2005: 39).

A pesar de estas diferencias con respecto a Correspondencias no se puede omitir, sin embargo, que las dos partes del libro se reducen a un fundamento común. En Sobre una confidencia del mar griego, tal y como en Correspondencias, el punto de fuga a partir del cual se proyecta la figura del sujeto es una negatividad fundadora. Lo atestiguan las referencias a la muerte, pero también a un trauma en el origen de la auto-constitución subjetiva («Esos signos herían» (Sánchez Robayna, 2005: 35); «la luz que martillea el yunque de este día», (2005: 53)). Lo atestigua también la página blanca, revalorizada en Sobre una confidencia del mar griego: si dominan en Correspondencias poemas con estrofas de dos o cuatro versos respectivamente, tropezamos, en Sobre una confidencia del mar griego, con poemas que combinan distintos tipos de estrofas, atrayendo así la atención a los espacios blancos; la misma función tiene el verso libre, más frecuente en Sobre una confidencia del mar griego.

La ojeada que acabamos de echar sobre Correspondencias y Sobre una confidencia del mar griego refleja una pequeña parte de los análisis que precedieron la traducción de los poemas. Me permitían valorar los elementos de los poemas según su importancia relativa dentro del poemario y destacar lo que podríamos llamar su identidad. Es evidente que intenté mantener los elementos que constituyen esta identidad en la medida de lo posible; así, a la hora de traducir el libro, los campos semánticos claves como el de la luz, del ver y del oír no se tocaron, mientras que me permití más

\footnotetext{
${ }^{1}$ Esbocé este sustrato narrativo en Bischoff (2013).
} 
libertades a la hora de traducir imágenes aisladas ${ }^{2}$. Es evidente también que intenté reconstruir, en el texto alemán, la dimensión metapoética presente en ambas partes del libro, lo que, sobre todo en Sobre una confidencia del mar griego, supuso un trabajo pormenorizado y todavía no cerrado para interpretar imágenes a veces oscuras. En el caso de Sobre una confidencia del mar griego, consideré además la dimensión narrativa introduciendo, en ocasiones, conectores que, como el alemán no diferencia entre el pretérito imperfecto y el pretérito indefinido, servían para relacionar los fragmentos entre $\mathbf{s i ̂}^{3}$. También tomé en cuenta el diseño de las estrofas y del verso sin pasar por alto la densidad semántica y la sencillez sintáctica del original:

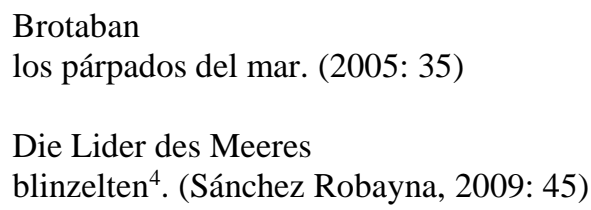

Más complejos que los casos que acabo de dibujar eran los casos en los que los distintos niveles de la constitución del texto entraban en juego a la hora de negociar una traducción posible del mismo. En Correspondencias y en Sobre una confidencia del mar griego, tanto la semántica como la sintaxis están marcadas por disyunciones que reflejan un proceso de apropiación del mundo por la conciencia subjetiva. El poema «Gerberas amarillas» es un ejemplo muy ilustrativo del estilo elíptico y despojado de elementos accesorios que domina en las dos partes del libro:

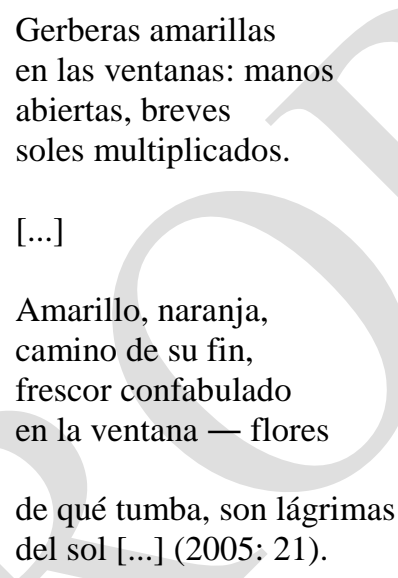

El incitamentum del poema, las gerberas amarillas vistas en una ventana, se encuentra trabajado, nada más mencionarlo, por la consciencia subjetiva. Las flores se transforman metafóricamente en manos abiertas y soles; sigue un proceso de abstracción en el que el color y el

\footnotetext{
${ }^{2}$ Para dar un ejemplo, la «música porosa» (Sánchez Robayna, 2005: 15), literalmente «poröse Musik», no se podía traducir así en un país de aficionados al coche y al bricolaje, donde «porös», inevitablemente, hace pensar en ruedas gastadas o en aislamientos térmicos. Traduje entonces «poroso», a partir de la falta de solidez que connota, por «brüchig» (Sánchez Robayna, 2009: 17), 'quebradizo'.

3 «Escuchaste, / casi inaudible» (2005: 39): «Dann ['entonces'] hörtest du, / kaum vernehmbar» (2009: 49). «Oyes de nuevo el mar» (2005: 71): «Und ['y'] wieder hörst du» (2009: 89). [Las cursivas son mías].

${ }^{4}$ Hubiera sido posible, para acercarse más al original, traducir de esta forma: «Es blinzelten / die Lider des Meeres». La sintaxis hubiera requerido sin embargo un «es» semánticamente vacío y por esto indeseable.
} 


\section{Javier Gómez Montero y Christina Johanna Bischoff}

frescor se disocian de ellas. Finalmente, las imágenes subjetivas se tuercen: los pequeños soles portadores del «poder de luz» se convierten, con «flores / de qué tumba», en los símbolos mismos de la muerte.

La estructura del poema atenúa las disyunciones semánticas. En la primera estrofa, los versos aseguran una continuidad entre los distintos sintagmas del poema («en la ventana: manos»), mientras que los encabalgamientos, a su vez, desmienten la ruptura que supone el verso ( «manos / abiertas», «breves / soles»). De manera parecida, la ruptura semántica, que se produce cuando al final de la tercera estrofa las imágenes esperanzadoras desembocan en una meditatio mortis, está dislocada de la ruptura que supone la transición de la tercera a la cuarta estrofa. La unidad del poema está en esta interrelación entre ruptura y ligazón escenificada por la semántica y la estructura del verso. Tomé en cuenta este aspecto a la hora de traducir, dejando aparte otros aspectos estructurales del poema como el diseño fonético o el número de sílabas:

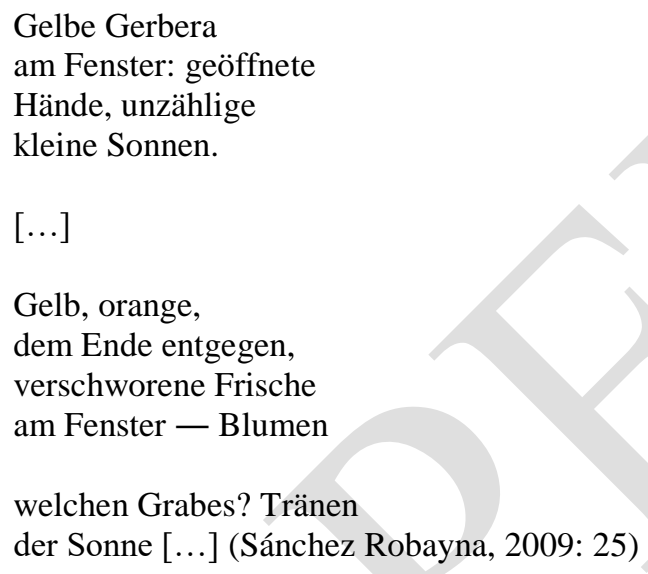

Encontramos, en Correspondencias, una serie de imágenes impactantes que apelan a los traumas sufridos por un imaginario colectivo y sublimados por la conciencia del sujeto lírico. Intenté 'salvar' tanto el impacto como la sublimación; como esta última, en Correspondencias, es esencialmente un asunto rítmico, las discusiones que tuvimos en el Taller de Kiel y en las conversaciones con Karina Gómez-Monterose hicieron escenario del conflicto originario de cualquier traducción, a saber el problema de balancear las exigencias semánticas con las exigencias más bien formales, como la fonética y el ritmo:

Pasan trenes en marzo atestados de lágrimas (Sánchez Robayna, 2005: 25)

(1) Die Züge im März sind voll Tränen

(2) Züge passieren im März, mit Tränen überfüllt

(3) Die Züge im März sind mit Tränen gefüllt (Sánchez Robayna, 2009: 31)

La propuesta (1) fue mi primera intuición a la hora de traducir el verso. Valora el ritmo en detrimento de la semántica: «Pasan trenes [...] atestados [...]» se convierte, en la traducción al alemán, en «los trenes están llenos de [...]». Fue Karina Gómez-Montero la que reclamó, con razón, la sustitución del verbo «pasar»y del participio «atestado» por el verbo copulativo, por lo tanto semánticamente vacío, «sein». La solución (2), que enfoca la dimensión semántica, tropezó sin 
embargo con la polisemia del verbo «passieren» en alemán, además de introducir una ruptura rítmica desconocida en el original. La propuesta (3), que adopté en la versión final de la traducción, no mantiene el «passieren», pero sí abandona el verbo copulativo «sind» en favor del verbo «füllen» en voz pasiva («sind [...] gefüllt»), tomando en cuenta también el ritmo del original.

En los poemas que acabamos de analizar, los incitamenta remiten a una realidad extratextual. Este tipo de comienzo es usual en un libro que se dedica a explorar los procesos de subjetivación efectuados por la consciencia subjetiva. La voz poética, en ambas partes del libro, suele originarse en observaciones, personas o incidencias dadas como objetos sobre los que actúa la consciencia subjetiva. Este procedimiento puede plantear problemas a la hora de traducir, ya que, como suelen apuntar las reflexiones corrientes acerca de la (in)traducibilidad de la poesía, los marcos cognitivos en las que se inscribe y que trabaja la poesía, varían según las culturas. Hay que decir que Sobre una confidencia del mar griego, la mayoría de las veces, evoca una realidad extratextual conocida en las dos culturas: gerberas, madera de una silla rota, personajes como Rachel Corrie y acontecimientos como el atentado del 11 de marzo de 2004 son, por muy distinta que pueda haber sido la recepción de este último en el país mismo donde pasó, elementos de una memoria cultural compartida. Aun así, el problema se daba en ocasiones en Sobre una confidencia del mar griego; en general opté por una adaptación a la cultura de destino. Así el «templo de cien puertas» (2005: 53), que designa una iglesia en la isla de Paros, se hizo «Tempel» en alemán, aunque el término, a diferencia del español, no designa edificios destinados a los cultos cristianos. El contexto, sin embargo, insinuaba esta solución confirmada, además, por Andrés Sánchez Robayna.

El inicio de este poema, «El niñodiós anduvo / por estas calles blancas: [...]» (2005: 19), alude a Juan Ramón Jiménez, un poeta muy poco conocido en Alemania; me atrevo a decir que la alusión al poeta andaluz es francamente irreconocible para un alemán. Un tanto más conocido, pero con connotaciones culturales distintas, es el niño al que Jiménez presta su auto-denominación: el «Jesuskind», el «dulce Jesús» de la devoción popular, o incluso el «Christkind», respuesta protestante a los Reyes Magos y personificación de los deseos navideños de generaciones de niños alemanes. Evidentemente, las dos traducciones no podían reproducir la polisemia del original; opté por «Kindgott», que, sin poder salvar la referencia al poeta de Moguer, deja sin embargo margen a asociaciones tanto religiosas como profanas.

Si mi intento era reconciliar, en la medida de lo posible, las exigencias semánticas y rítmicas en la traducción alemana, queda entendido que no pude respetar de manera igual el nivel fonético de los poemas. Coincido con Monika Fahrenbach-Wachendorff (2014), la traductora de las Flores del Mal al alemán, cuando observa que no es aceptable valorar el sonido dando la espalda a la semántica de las palabras. Si aparecía una solución convincente, le daba la bienvenida:

Era la espera, el mar de amanecer / [...] (2005: 37)

Warten am Morgenmeer / [...] (2009: 47) 
Sin embargo, no intenté forzar soluciones 5 .

La traducción al alemán de Sobre una confidencia del mar griego hacía hincapié en el diseño semántico, sintáctico y métrico del libro, intentando reconstruir las múltiples relaciones — sea de consonancia o de contraste- que establecen estos niveles del texto entre sí. Su meta era recrear los efectos de sentido propuestos por el texto original. El proceso de negociación, sin embargo, no se ha cerrado con la publicación del libro: Sobre una confidencia del mar griego es, como el «centelleo de las aguas quietas» que el yo lírico contempla en el mar griego, un «murmullo» (Sánchez Robayna, 2005: 71) polifacético que refleja una multitud de lecturas posibles y, desde luego, inabarcables por cualquier traducción.

\section{Bibliografía}

Bischoff, C. J. (2013): «“Cada cosa tenía un Dios, dijiste?”. Diálogo y silencio en Sobre una confidencia del mar griego de Andrés Sánchez Robayna», en C. J. BischOFF - A. THIEM, eds., Poesía y silencio. Berlín, LIT.

ECO, U. (2003): Mouse or Rat? Translation as Negotiation. London, Phoenix.

FAHRENBACH-WACHENDORFF, M. (2014): «Formale Aspekte der Lyrikübersetzung: Les Fleurs du Mal von Charles Baudelaire», en http://www.xn--bersetzerwerkstatt-erlangen-h3c.de/de/ formale-aspekte-der-lyrik\%C3\%BCbersetzung-les-fleurs-du-mal-von-charles-baudelaire (última consulta, 28-01-17).

SÁnchez RobAyna, A. - TÀPIES, A. (2005): Sobre una confidencia del mar griego. Precedido de Correspondencias. Madrid, Signos.

(2009): Was das griechische Meer mir anvertraute. Spanisch und deutsch. Trad. C. J. BISCHOFF. Kiel, Ludwig.

\footnotetext{
${ }^{5}$ Así, en el caso de la estrofa en cuestión, una propuesta hecha a lo largo de una presentación del poema, en una reunión de los traductores del Taller de Traducción Literaria en Kiel, fue: «Warten wars am Morgenmeer». A pesar de que se reprodujera, con «Warten wars», la consonancia de «era [...] espera», no me pareció admisible tanto por el peso que la expresión, algo inusual en alemán, le da a la primera parte del verso, como por el predominio que adquiría el fricativo, por su repetición, frente al predominio de las vocales en el original.
} 